\title{
Rearing Larvae of Different Strains of Coregonus lavaretus under Cold Water Conditions: Comparison of a Special Cold-Water Line with a Standard Agglomerated Microdiet
}

\author{
Stephanie Leithner ${ }^{1} \&$ Josef Wanzenböck ${ }^{2}$ \\ ${ }^{1}$ Organismic Biology, University of Salzburg, Salzburg, Austria \\ ${ }^{2}$ Research Institute for Limnology, University of Innsbruck, Mondsee, Austria \\ Correspondence: Stephanie Leithner, Organismic Biology, University of Salzburg, Hellbrunnerstraße 34, 5010 \\ Salzburg, Austria. E-mail: stephanie.leithner@stud.sbg.ac.at
}

\author{
Received: February 8, 2015 Accepted: March 11, 2015 Online Published: April 15, 2015 \\ doi:10.5539/jas.v7n5p28 URL: http://dx.doi.org/10.5539/jas.v7n5p28
}

\begin{abstract}
We studied the performance of a commercial, agglomerated larval microdiet in terms of survival, growth and feed acceptance and compared a dedicated "cold water line" of the product to the standard product involving a Baltic and an Alpine strain of whitefish. Experiments were conducted under cold water conditions $<8{ }^{\circ} \mathrm{C}$ (average $5.1^{\circ} \mathrm{C}$ ) for 60 days after hatching. Replicate tanks of 400 and 200 liter volume received filtered lake water disinfected with ozone and UV light and were stocked with 15 larvae per liter. Daily rations of $4 \%$ body weight were manually delivered in six portions every two hours and group samples were taken weekly to determine length, weight and feed acceptance. Dead larvae were removed and counted daily. Before our experiment was influenced by an outbreak of an unknown disease during the last two weeks, we observed similar growth, survival and feed acceptance for each of the feed types with low variability within each of the two strains. Strains showed characteristic differences in growth and survival related to lower feed acceptance during the first four weeks of the Alpine strain. We concluded that the specific cold water line of the commercial microdiet did not provide any advantage compared to the standard product under low temperature conditions. However, differential performance might exist under different temperature regimes.
\end{abstract}

Keywords: European whitefish, growth, survival, feed acceptance, AgloNorse ${ }^{\circledR}$

\section{Introduction}

The industrialization and intensification of fish production in Europe (mainly trout and salmon) started in the 1960s when the industry demanded better and more balanced food products (Goddard, 1996). However, for sensitive fish species, such as European whitefish, the developed feeds seemed to be of limited suitability as shown in many studies during the 1970s, 1980s and 1990s (Eckmann \& Kausch, 1976; Rösch \& Dabrowski, 1986; Rösch, 1988; Koskela \& Eskelinen, 1992). These studies were rarely satisfactory because at this time available dry feeds (extruded feeds) often included insufficient qualitative and quantitative nutrient composition for whitefish larvae and they starved to death (Kummer \& De Verga, 1992). More recently the industry increasingly uses the process of agglomeration to improve performance of starter feeds (microdiets) for small larvae of mainly marine species. Through this process, individual particles are enlarged in order to facilitate handling and to avoid dust formation (Langdon \& Barrows, 2011; Holt et al., 2011). However, the suitability of these agglomerated dry feeds has not been extensively tested for whitefish respectively published.

Previous studies showed that rearing of European whitefish under cold-water conditions $\left(<8{ }^{\circ} \mathrm{C}\right)$ was difficult and survival rate increased with increasing water temperature (Rösch, 1988; Koskela \& Eskelinen, 1992; Rojas Beltran et al., 1992). However, in most hatcheries the ambient water temperatures during early spring, when whitefish hatch, are low and water warming takes considerable energy and thus may not be economically viable. At the same time, producers of microdiets for marine fish larvae propagated special "cold-water" lines of their microdiets (e.g. AgloNorse ${ }^{\circledR}$ distributed by Ewos in 2006/2007) for which improved success was reported with cod compared to the standard product (pers. communication). This cold-water line differed from the standard product in proportion of highly unsaturated fatty acids (for details see Material \& Methods). Therefore, the question arose to which extent special "cold-water" microdiets show improved performance also for whitefish 
larvae under ambient low water temperatures $\left(<8^{\circ} \mathrm{C}\right)$.

Rearing of whitefish larvae is of variable success and a large part of this variability depends on the strain used for experiments (Rösch \& Dabrowski, 1986; Mahmoudzadeh et al., 2009). Consequently results cannot reliably be transferred to other strains (Rösch, 1992) or species (the taxonomy of European whitefish is a matter of intensive debate) e.g. from Baltic/Scandinavian strains to those of the central European region of the Alps. Potentially the latter strains might have advantages in marketing as regional special products. However, aquaculture of Alpine whitefish is considerably less developed compared to Baltic and Scandinavian strains (Siikavuopio et al., 2012).

The aim of our study was to compare rearing success in terms of growth, survival and feed acceptance of two whitefish strains (Baltic vs. Alpine) using a special "cold-water" and a standard agglomerated commercial microdiet under ambient cold-water conditions.

\section{Materials and Methods}

\subsection{Experimental Design and Conditions}

In winter 2011/2012 eggs of European whitefish (Coregonus lavaretus), from an existing breeding line originating from whitefish of the southern Baltic region (sometimes designated Coregonus maraena) and reared since the $19^{\text {th }}$ century in carp-pond aquaculture in Bohemia and northern Austria (Susta, 1888; Winkler et al., 2011) and bred in our own hatchery in the fourth generation were stripped and artificially fertilized. The offspring of these fish is thereafter called strain 1. Native whitefish (Coregonus lavaretus) from the Austrian lake "Hallstättersee" (designated Coregonus renke by Kottelat \& Freyhof, 2007) were caught in early December 2011 and wild fish were stripped to form the first hatchery generation of what is referred to in the following as strain 2 . The fertilized eggs were incubated in incubation vessels (Zuger jars) at a temperature of $4-5{ }^{\circ} \mathrm{C}$ in our hatchery in Mondsee, Austria. The experiment started a few days after hatching on 08.02.2012 and encompassed the first 60 days of development which covered the most sensitive phase of whitefish larvae when changes from endogenous to exogenous feeding occurs. Because of technical restrictions we had to use tanks of different sizes: Replicate groups of 6000 larvae were reared in round PVC tanks of 400 liters volume or 3000 larvae in tanks of 200 liters volume. All test tanks received water pumped from the lake at $10 \mathrm{~m}$ depth, filtered by a sand filter and treated with Ozone and UV light. For strain 1 four tanks were used (two big and two small tanks) and for strain 2 six tanks were used (three big and three small tanks). The exchange rate of the water per tank was set to 1.0 times per hour. Within the first 3 - 4 weeks feeding was started with 100 to $200 \mu \mathrm{m}$ particles, and during the next 3 - 4 weeks feeding continued with 200 to $300 \mu \mathrm{m}$ particles maintaining a daily ration of $4 \%$ body weight per day. Feed was delivered manually in six portions every two hours. Tanks were siphoned daily to remove faeces, food residues and eventually dead larvae. Motionless larvae lying on the bottom were considered dead, siphoned off and counted. Water quality parameters (temperature, $\mathrm{pH}$, redox potential) were recorded by means of probes in intervals of 30 minutes and logged. A sample of 30 individuals per tank was collected weekly to determine fresh weights to the nearest $0.1 \mathrm{mg}$. For this purpose, larvae were sacrificed with an overdose of the anesthetic phenoxyethanol, blotted of paper towels and then weighed using an analytical balance. Subsequently they were placed under a dissecting microscope to determine if food particles were visible in the gut of the larvae.

\subsection{Feed Types}

A special agglomerated larval starter feed, originally developed for marine fish species called "AgloNorse ${ }^{\circledR}$ ", i.e. the standard product and "AgloNorse ${ }^{\circledR}$ Extra", replacing the "cold-water" version of 2006/2007 (Tromsø Fiskeindustri AS, Norway) was used in our experiment. The composition of the dry feed was: $58-60 \%$ protein, $17-20 \%$ fat, $10 \%$ ash, $1 \%$ fibre and 7-9\% moisture. The only difference between the two types of feed was in the percentage of the n-3 PUFA and n-6 PUFA ("AgloNorse®": 2.1-2.6\% PUFA n-3 and 2.5-2.6\% PUFA n-6; "AgloNorse ${ }^{\circledR}$ Extra": 3-3.5\% PUFA n-3 and 1.3\% PUFA n-6).

\subsection{Statistical Analysis}

Numbers of survivors per tank were calculated daily by subtracting dead individuals from the initial number minus those collected for measurements or after extensive cleaning. Before any statistical analysis, the metric data were checked for normal distribution and for equal variance, and optionally log transformation (log (data)) was applied. Analysis of Covariance (ANCOVA) was used as a test procedure for the significance of the growth data including time as a co-variable. As a second test for significance, student's t-test was chosen. If data were not normally distributed or equal variance was not given, despite transformation, a nonparametric test, i.e. the Mann-Whitney Rank Sum test, was used. 


\section{Results}

The initial lengths of the larvae were significantly different $(12.37 \pm 0.34 \mathrm{~mm}$ for strain 1 and $10.89 \pm 0.76 \mathrm{~mm}$ for strain 2, Mann-Whitney test: $\mathrm{P}=<0.001$, Strain $1 \mathrm{n}=90$ and strain $2 \mathrm{n}=87$ ). Also the initial weights of the two whitefish strains at the start of the experiment were significantly different $(7.9 \pm 1.1 \mathrm{mg}$ for strain 1 and 6.5 $\pm 1.0 \mathrm{mg}$ for strain 2, Mann-Whitney test: $\mathrm{P}=<0.001$, Strain $1 \mathrm{n}=120$ and strain $2 \mathrm{n}=180$ ). Water temperature was very low at the beginning of the experiment, at about $3{ }^{\circ} \mathrm{C}$ (Table 1), due to an exceptionally cold weather period. Subsequently, a slowly rising trend in temperatures was observed but never reached $7^{\circ} \mathrm{C}$. The average temperature during the experiment was $5.1 \pm 1.2{ }^{\circ} \mathrm{C}$.

Table 1 . Weekly average temperature and relative growth rate (RGR)

\begin{tabular}{|c|c|c|c|c|c|c|}
\hline & & & \multicolumn{2}{|c|}{ Strain 1} & \multicolumn{2}{|c|}{ Strain 2} \\
\hline & & & AgloNorse ${ }^{\circledR}$ & AgloNorse ${ }^{\circledR}$ Extra & AgloNorse ${ }^{\circledR}$ & AgloNorse ${ }^{\circledR}$ Extra \\
\hline Date & Week & $\begin{array}{l}\text { Weekly average } \\
\text { temperature }\end{array}$ & RGR & RGR & RGR & RGR \\
\hline $8-15$ February & 1 & $3.24 \pm 0.37$ & 0.006 & 0.006 & 0.019 & 0.032 \\
\hline $16-23$ February & 2 & $3.93 \pm 0.22$ & 0.011 & 0.011 & 0.000 & -0.015 \\
\hline $24-29$ February & 3 & $4.36 \pm 0.14$ & 0.019 & 0.018 & -0.001 & -0.004 \\
\hline $01-07$ March & 4 & $5.00 \pm 0.14$ & 0.014 & 0.015 & 0.000 & 0.006 \\
\hline $08-14$ March & 5 & $5.11 \pm 0.19$ & 0.022 & 0.024 & 0.028 & 0.025 \\
\hline $15-21$ March & 6 & $6.16 \pm 0.28$ & 0.026 & 0.018 & 0.025 & 0.020 \\
\hline $22-28$ March & 7 & $6.45 \pm 0.20$ & -0.007 & 0.016 & 0.028 & 0.029 \\
\hline 29 March - 04 April & 8 & $6.37 \pm 0.46$ & 0.002 & 0.027 & 0.030 & 0.004 \\
\hline
\end{tabular}

Note. Weekly average temperature and relative growth rate (RGR) of the different strains and feed during the experiment. Data are presented as weekly means \pm standard deviations.

The major differences between strains and feed types are summarized in Figures 1a and 1b representing measured mean weights of all replicate tanks: For strain 1 we observed mean constant growth for the entire experimental period for "AgloNorse ${ }^{\circledR}$ Extra" (high standard deviation occurred because larvae of one of the replicate tanks grew considerably less from day 40 onwards) and declining weights for "AgloNorse ${ }^{\circledR}$ " during the last two weeks. For strain 2, stagnant average weights were evident for both feed types until day 30, followed by continuous mean growth in the "AgloNorse ${ }^{\circledR}$ " groups. A halt in growth was observed in strain 2 for "AgloNorse ${ }^{\circledR}$ Extra" during the last week. For the entire experimental period, the measured mean fresh weight did not differ significantly between groups receiving different feed types in strain 2, however, it differed in strain 1 (data were transformed and tested using ANCOVA. Strain 1: $\mathrm{n}=960, \mathrm{P}=0.004$ and strain $2: \mathrm{n}=1440, \mathrm{P}=$ 0.541). However, also in strain 1, fresh weights were similar in each of the first six weeks (Student's t-test, p-values between 0.672 and $0.985, n=30$ for "AgloNorse ${ }^{\circledR}$ " and $n=30$ for "AgloNorse ${ }^{\circledR}$ Extra"). In strain 2 fresh weights were similar in each of the first seven weeks (Student's t-test and Mann-Whitney test, p-values between 0.031 and $0.887, \mathrm{n}=30$ for "AgloNorse ${ }^{\circledR}$ " and $\mathrm{n}=30$ for "AgloNorse ${ }^{\circledR}$ Extra"). 

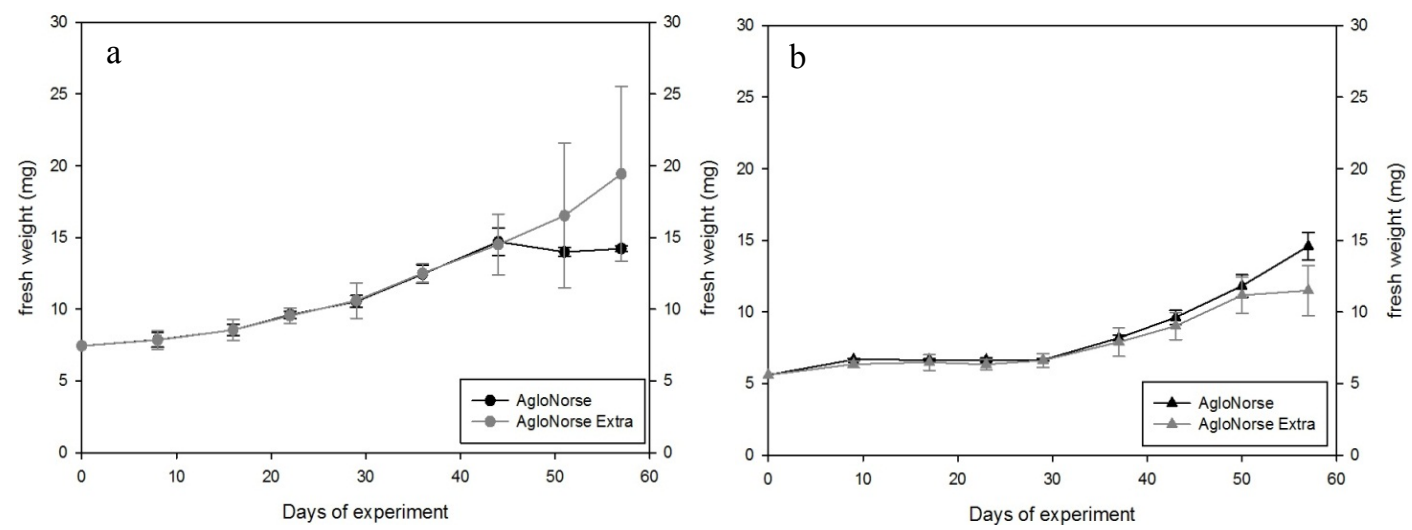

Figure 1. Growth curves

Note. Growth curves for different feed types and different fish strains including mean weights \pm standard deviation of all replicate tanks: a) Strain 1: "AgloNorse ${ }^{\circledR}$ " and "Aglo Norse ${ }^{\circledR}$ Extra". b) Strain 2: "AgloNorse ${ }^{\circledR}$ " and "AgloNorse ${ }^{\circledR}$ Extra".

The final weight of strain 1 differed significantly between the two feed types $(\mathrm{P}=<0.001$, Mann-Whitney test on transformed data) and was $14.2 \pm 0.2 \mathrm{mg}(\mathrm{n}=60)$ for "AgloNorse ${ }^{\circledR}$ " and $19.4 \pm 6.6 \mathrm{mg}(\mathrm{n}=60)$ for "AgloNorse ${ }^{\circledR}$ Extra". Also the final weights of strain 2 differed significantly between the two feed types $(\mathrm{P}=<$ 0.001, Mann-Whitney test on transformed data). The final weight for "AgloNorse ${ }^{\circledR}$ " was $14.6 \pm 4.2 \mathrm{mg}(\mathrm{n}=90)$ and for "AgloNorse ${ }^{\circledR}$ Extra" was $11.5 \pm 3.8 \mathrm{mg}(\mathrm{n}=90)$.

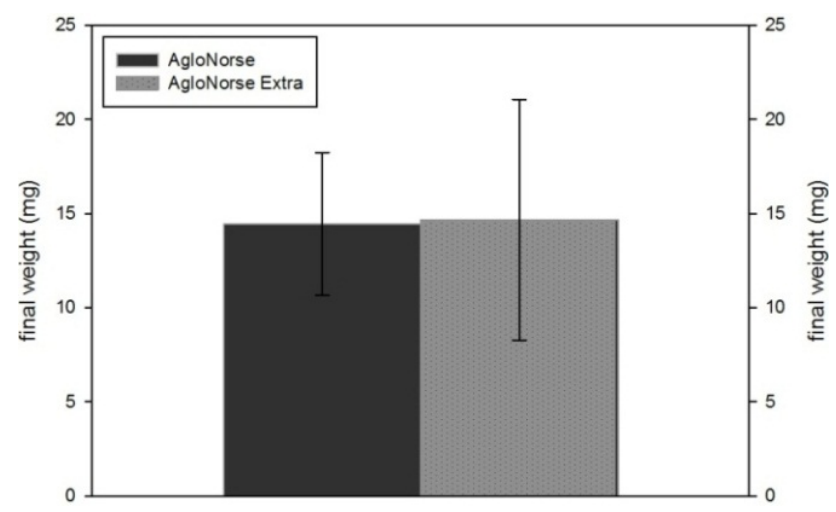

Figure 2. Comparison of feed types

Note. Comparison of the two types of feed. Bars illustrate mean \pm standard deviation of final fresh weight (mg) of all larvae regardless to the strain.

For "AgloNorse ${ }^{\circledR}$ ", there was no statistically significant difference $(P=0.772$, Mann-Whitney test on transformed data, strain $1: \mathrm{n}=60$ and strain $2: \mathrm{n}=90$ ) between final weights of strain 1 and strain 2 . However, for "AgloNorse ${ }^{\circledR}$ Extra", there was a statistically significant difference between final weights of strain 1 and strain $2(\mathrm{P}=<0.001$, student's t-test on transformed data, strain 1: $\mathrm{n}=60$ and strain $2: \mathrm{n}=90)$. Comparing the two types of feed, combining all fish without regard to the strain, no statistically significant difference was found in final weights (Figure 2, $\mathrm{P}=0.283$, Mann-Whitney test on transformed data, "AgloNorse ${ }^{\circledR} ": \mathrm{n}=150$ and "AgloNorse ${ }^{\circledR}$ Extra": $\mathrm{n}=150$ ).

In terms of relative growth rate, there was no statistically significant difference within strain 1 and strain 2 (Table 1), based on the different types of feed (ANCOVA: strain 1: $P=0.174$, "AgloNorse ${ }^{\circledR} " ~ n=14$ and for “AgloNorse ${ }^{\circledR}$ Extra" $n=14$. Strain 2: $\mathrm{P}=0.126$, “AgloNorse ${ }^{\circledR} " \mathrm{n}=21$ and for "AgloNorse ${ }^{\circledR}$ Extra" $\mathrm{n}=21$ ). Within the two feed types, there were also no statistically significant differences in relative growth rates between strain 1 and strain 2 (ANCOVA: "AgloNorse ${ }^{\circledR}$ ": $\mathrm{P}=0.480$, strain $1 \mathrm{n}=14$ and strain $2 \mathrm{n}=21$. "AgloNorse ${ }^{\circledR}$ Extra": $\mathrm{P}=0.076$, strain $1 \mathrm{n}=14$ and strain $2 \mathrm{n}=21$ ). 
Comparing the two types of feed in the relative growth rates, combining all fish without regard to strain, no statistically significant difference was found (ANCOVA: $P=0.645$, "AgloNorse ${ }^{\circledR}$ " $n=35$ and "AgloNorse ${ }^{\circledR}$ Extra" $\mathrm{n}=35$ ). Comparing the two strains in the relative growth rates, combining all fish without regard to feed type, no statistically significant difference was found (ANCOVA: $P=0.423$, strain $1 \mathrm{n}=28$ and $\operatorname{strain} 2 \mathrm{n}=42$ ).

The survival rates were different for the two strains and partly also for groups receiving different feed types (Figure 3). In strain 1 the survival rates remained very high for six weeks for both groups and started to decrease around day 40. The group receiving "AgloNorse ${ }^{\circledR}$ " showed strongly declining survival with lower variability as both replicate tanks were affected with high mortality. The group receiving "AgloNorse $₫$ Extra" showed high variability as only in one replicate tank elevated mortality was observed. This resulted in a final average survival rate of $47.5 \%$. There was a statistically significant difference in average survival between groups (ANCOVA: $\mathrm{P}=$ $0.003, \mathrm{n}=120$ for both feed types). For strain 2 the survival rate started to decrease much earlier, at day 30 of the experiment. There was noticeable increase of mortality at this time in all replicate tanks. However, unlike strain 1 , the decline in survival stopped around day 40 and remained constant for about ten days before the two groups diverged. We observed a second decline in survival in one group ("AgloNorse ${ }^{\circledR}$ Extra") but not in the other group (“AgloNorse ${ }^{\circledR}$ "). The average final survival rate of strain 2 was $45.58 \%$ for "AgloNorse ${ }^{\circledR}$ " and $37.32 \%$ for "AgloNorse ${ }^{\circledR}$ Extra", with relatively low variability. There was no statistically significant difference in survival of strain 2 (ANCOVA: $\mathrm{P}=0.277, \mathrm{n}=190$ for both feed types) between the two types of feed.
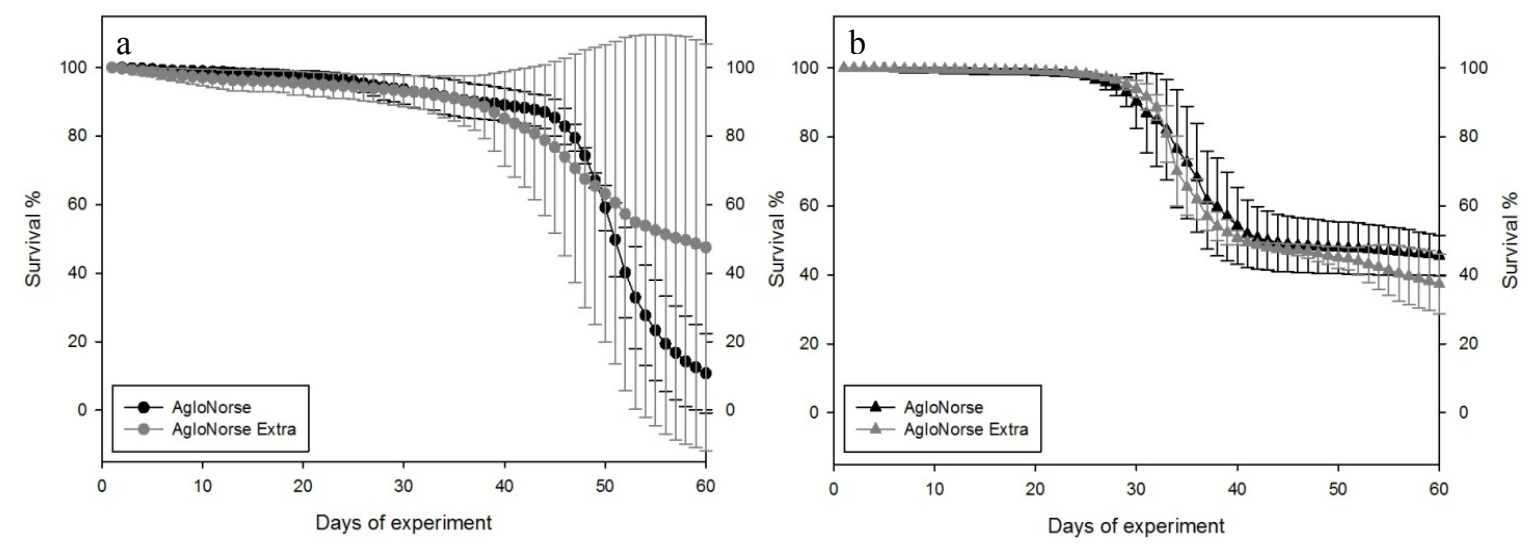

Figure 3. Survival rate

Note. a) Survival rate (\%) of strain 1. b) Survival rate (\%) of strain 2. Data are presented as daily average of survival rate \pm standard deviation.

Comparing the two different feed types without regard to the strain, there was no statistically significant difference (ANCOVA: $\mathrm{P}=0.123, \mathrm{n}=300$ for both feed types). However comparing the strains without regard to the different types of feed, there was a statistically significant difference (ANCOVA: $\mathrm{P}=0.001, \mathrm{n}=240$ for strain 1 and $n=360$ for strain 2), i.e. strain 1 showing lower survival.

At the beginning, strain 1 accepted the offered feed faster than strain 2. Towards the end of the experiment differences disappeared and reached almost $100 \%$ (Figure 4). There was a statistically significant difference between the strains (ANCOVA: $\mathrm{P}=0.000$; strain $1 \mathrm{n}=29$ and strain $2 \mathrm{n}=48$ ). But between the types of feed there was no statistically significant difference in strain 1 nor in strain 2 (ANCOVA: Strain 1: $\mathrm{P}=0.699$, "AgloNorse ${ }^{\circledR} " \mathrm{n}=16$ and "AgloNorse ${ }^{\circledR}$ Extra" $\mathrm{n}=16$, Strain 2: $\mathrm{P}=0.971$, "AgloNorse ${ }^{\circledR} " \mathrm{n}=24$ and “AgloNorse ${ }^{\circledR}$ Extra" $\left.n=24\right)$. 


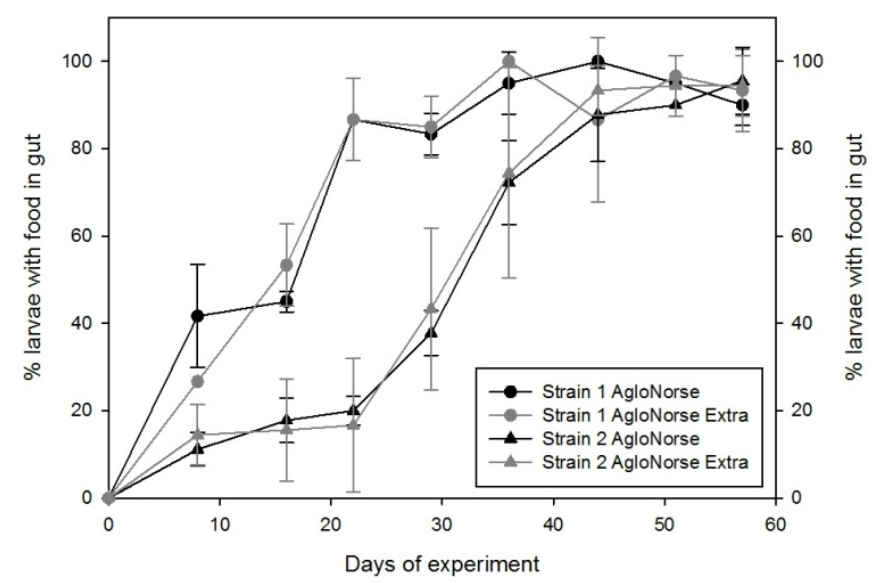

Figure 4. Feed acceptance

Note. Feed acceptance of strains. Data are represented as mean \pm standard deviation.

\section{Discussion}

\subsection{Identifying the Time Period for Valid Comparisons}

Our results were influenced by an unidentified disease towards the end of the experiment. Therefore, the potential influence has to be assessed and separated from other factors to be investigated, i.e. strain and feed type.

For strain 1, the experiments were clearly influenced by disease during the last two weeks as seen in a complete halt of growth in the test group receiving feed "AgloNorse ${ }^{\circledR}$ " (in which all replicate tanks were affected, Figure 1a) and in the distinct increase of variance in the group receiving feed "AgloNorse ${ }^{\circledR}$ Extra" (in which one replicate tank was affected, Figure 1a). Up until day 45 the growth curves do not show any sign of disease influence, i.e. low variance, and the survival curves (Figure 3a) also show high survival of $80 \%$ until day 40 , before plunging down. Therefore, we are confident to make valid comparisons in this strain during the first six weeks of the experiment.

For strain 2, we observed almost identical and low-variance growth curves until day 50 and diverging average weights only during the last week (Figure 1b). This corresponds to almost identical survival curves with noticeable differences appearing during the last ten days (Figure $3 b$ ). The group receiving "AgloNorse ${ }^{\circledR}$ " was not affected by the disease in none of the three replicate tanks and variances in weights and survival remained low (Figures $1 \mathrm{~b}$ and $3 \mathrm{~b}$ ). For the group receiving "AgloNorse ${ }^{\circledR}$ Extra" one of three replicate tanks was affected which resulted in lower average weight and elevated variability compared to the first group of strain 2 (Figure 1b). For this strain we are convinced to make valid comparisons for the first 7 weeks of the experiment. Although the number of replicates of the performed experiment was relatively small, the variation among replicates was extremely low before disease outbreak. Therefore, the number of replicates used was considered sufficient.

\subsection{Comparisons of Feed Types}

During six weeks before disease outbreak, a steadily increasing growth curve with very low variance was registered in strain 1 and with both feed types (Figure 1a). The average weights in each of the six weeks were almost identical among different feed types and the relative growth rates were largely similar as well (Table 1). Therefore, it seems evident that feed type did not lead to any observable differences between groups of strain 1 , neither in growth (Figure 1a) nor in survival (Figure 3a) or feed acceptance (Figure 4). Divergence of the two groups receiving different feed types was observed during the last two weeks of our experiment and was clearly associated with disease outbreak. This affected the two groups differently (all replicate tanks in one group vs. one replicate tank in the other group), however, we suspect this was unrelated to feed type.

For strain 2 we observed almost constant average weights over time for the first four weeks followed by steadily increasing weights for the following three weeks before disease outbreak. This pattern was found to be identical for both groups receiving different feed types and average weights were similar in the two groups in each of the seven weeks. Within that time period there was no indication of feed type leading to differences in growth, survival or feed acceptance in strain 2. Divergence of the two groups with regard to growth (Figure 1b, Table 1) 
and survival (Figure 3b) during the last week were again associated with differential affection of the two groups by disease.

Even if the influence of disease is ignored, no significant difference in final weights of fish receiving the different feed types was found when fish of both strains were pooled (Figure 2). To our knowledge, no previous study has investigated dedicated cold-water feed types and compared their performance to regular feed types. Most previous studies on whitefish compared feed types of vastly varying ingredients in experimental feeds (Luczynski et al., 1986; Dabrowski \& Poczyczynski, 1988; Harris \& Hulsman, 1991) or commercial microdiets of different manufacturers (Koskela \& Eskelinen, 1992, Rojas-Beltran et al., 1992, Rissanen, 1995). In those cases, the observed differences in performance of whitefish larvae might be of little surprise, however, our results provide evidence that one dedicated cold-water microdiet ("AgloNorse ${ }^{\circledR}$ Extra") does not provide advantages compared to the regular product ("AgloNorse ${ }^{\circledR}$ ") of the same manufacturer. In that respect, whitefish larvae seem to react differently to the two feed variants compared to cod (pers. 6 communication).

\subsection{Comparison of Strains}

For the time period before disease outbreak we observed considerable differences between strains with regard to growth and survival. These differences most probably have their common source in the differences regarding feed acceptance which was clearly delayed in strain 2 compared to strain 1 (similarly in both feed types, Figure 4). The feed acceptance in strain 1 increased quickly for both feed types which lead to increasing weights right from the start of the experiment and to low mortalities. For strain 2 the feed acceptance rates remained low for the first three weeks. Individuals which did not feed and lost weight outbalanced those feeding and gaining weight and therefore, average weights remained almost constant. Individuals refusing to accept the dry feed could probably live on their yolk reserves until day 25 after which survival started to drop in strain 2 . Concurrently the rate of feed acceptance apparently rose as "refusers" were dying off. Similarly the average weight started to increase and average growth rates attained the levels of strain 1 . This process was nearly finished around day 40 when survival remained constant and feed acceptance rates as well as growth rates had reached the levels of strain 1 . The following week strain 1 was partly influenced by the disease and strain 2 was partly influenced one week later making further comparisons difficult. However, when only unaffected tanks are taken into consideration, we did not find noticeable differences among strains. Strain 1 was hit harder and earlier by the disease compared to strain 2 resulting in lower survival and partly losing its initial growth advantage to end up in similar final weights, at least in the "AgloNorse ${ }^{\circledR}$ " group.

Differences in strains also found in previous studies (Rösch \& Dabrowski, 1986; Rösch, 1988, 1992). Similarly much of the differences were found to originate from differential feed acceptance. It remains unclear why such differences exist and if domestication might increase feed acceptance in a certain strain. Our results indicate that this might be the case because strain 1 is regarded more domesticated, i.e. adapted to hatchery conditions, compared to strain 2.

\subsection{Agglomerated Microdiets Compared to Previous Ones}

It seems that agglomerated microdiets can reach at least similar performance as previously used ones (Lucynski et al., 1986; Rösch \& Dabrowski, 1986) even under cold-water conditions. Survival of around $50 \%$ has been reported (Lucynski et al., 1986; Rösch \& Dabrowski, 1986) in studies using "old generation" microdiets, however, they were performed under more favorable, higher water temperatures $\left(>8^{\circ} \mathrm{C}\right)$. As we know from previous studies, food particle must be in an adequate physical structure so that they are readily digestible for whitefish larvae and nutritious enough to provide sufficient energy for growth (Holt et al., 2011; Langdon \& Barrow, 2011). Food acceptance is strongly influenced by the aroma of the food (Appelbaum, 1980; Dabrowski et al., 1984) and therefore "AgloNorse ${ }^{\circledR}$ " as well as "AgloNorse ${ }^{\circledR}$ Extra" are suspected to allow the larvae to smell the food particles and to identify them as a tempting meal (Kolkovski et al., 1997; Yúfera et al., 2002). Because the exact composition of the tested feed is a company secret, no detailed information can be given due to the missing data.

\subsection{Water Conditions}

Cold-water conditions $\left(<8^{\circ} \mathrm{C}\right)$ seem to be sufficient for the very early period of larval development (2-3 weeks) of whitefish but appear to exert negative influences during later development. If disease outbreak after six, respectively seven weeks was facilitated by cold-water conditions remains unclear, as disease outbreaks have been reported under higher temperatures as well (Dabrowski et al., 1984; Lucynski et al., 1986; Dabrowski \& Poczyczynski, 1988). But it is noticeable that disease outbreak was recognized in those studies exclusively at higher water temperatures $\left(>8^{\circ} \mathrm{C}\right)$. A shift of optimal temperatures during larval/juvenile development is known for many temperate species, e.g. nose carp (Keckeis et al., 1999) and is probably highly pronounced in whitefish. 
Anyhow, a test of agglomerated microdiets developed for marine fish larvae under higher water temperature regimes would be the next logical step to be performed using whitefish.

\section{Acknowledgements}

This study was funded by the Austrian Research Promotion Agency (FFG), under the "Bridge" program project number 827556. Sincere thanks are given to the Federal Austrian Forest Agency (Österreichische Bundesforste AG) for their cooperation, financial support and the supply with fish from lake Hallstatt. Franz Lahnsteiner and Sabine Wanzenböck provided helpful comments to improve an earlier version of this manuscript, which is appreciated very much.

\section{References}

Appelbaum, S. (1980). Versuche zur Geschmacksperzeption einiger Süsswasserfische im larvalen und adulten Stadium. Arch. Fisch. Wiss., 31, 105-114.

Dabrowski, K., \& Poczyczynski, P. (1988). Laboratory experiment and mass rearing of coregonid fish fed exclusively dry diets. Aquaculture, 69, 307-316. http://dx.doi.org/10.1016/0044-8486(88)90338-9

Dabrowski, K., Charlon, N., Bergot, P., \& Kaushik, S. (1984). Rearing of coregonid (Coregonus schinzi palea Cuv. et Val.) larvae using dry and live food, I. Preliminary data. Aquaculture, 41, 11-20. http://dx.doi.org/10.1016/0044-8486(84)90385-5

Eckmann, R., \& Kausch, H. (1976). Fütterung von Felchenbrut mit künstlichen Futtermitteln. In der Fischwirt, 26, 9-11.

Goddard, S. (1996). Feed management in intensive aquaculture. Capman \& Hall (Hrsg.). http://dx.doi.org/10.1007/978-1-4613-1173-7

Harris, K. C., \& Hulsman, P. F. (1991). Intensive culture of lake whitefish (Coregonus clupeaformis) from larvae to yearling size using dry feeds. Aquaculture, 96, 255-268. http://dx.doi.org/10.1016/0044-8486(91)90156-2

Holt, G. J., Webb, K. A., \& Rust, M. B. (2011). Microparticulate diets: testing and evaluating success. In G. Joan (Ed.), Holt Larval Fish Nutrition (pp. 353-372). John Wiley \& Sons. http://dx.doi.org/10.1002/9780470959862.ch13

Keckeis, H., Bauer-Nemeschkal, E., Menshutkin, V., Nemeschkal, H. L., \& Kamler, E. (1999). Effects of female attributes and egg properties on offspring viability in a rheophilic cyprinid, Chondrostoma nasus. Canadian Journal of Fisheries and Aquatic Sciences, 57, 789-796. http://dx.doi.org/10.1139/cjfas-57-4-789

Kolkovski, S., Koven, B., \& Tandler, A. (1997). The mode of action of Artemia in enhancing utilization of microdiet by gilthead seabream Sparus aurata larvae. Aquaculture, 155, 193-205. http://dx.doi.org/10.1016/s0044-8486(97)00117-8

Koskela, J., \& Eskelinen, U. (1992). Growth of larval European whitefish (Coregonus lavaretus) at different $\begin{array}{lllll}\text { temperatures. } & \text { Polskie } & \text { Archiwum }\end{array}$ http://dx.doi.org/10.1016/s0044-8486(03)00275-8

Kottelat, M., \& Freyhof, J. (2007). Handbook of European freshwater fishes (pp. 1-646). Kottelat, Cornol, Switzerland and Freyhof, Berlin, Germany, Publications Kottelat. http://dx.doi.org/10.1643/ot-08-098a.1

Kummer, H., \& De Verga, V. (1992). Vergleich unterschiedlicher Futtermittel bei der Aufzucht von Coregonenund Seesaiblingsbrut in künstlichen Systemen. Österreichs Fischerei, 45, 267-276.

Langdon, C., \& Barrow, R. (2011). Microparticulate diets: Technology. In G. Joan (Ed.), Holt Larval Fish Nutrition (pp. 305-351). John Wiley \& Sons. http://dx.doi.org/10.1002/9780470959862.ch12

Luczynski, M., Majkowski, P., Bardega, R., \& Dabrowski, K. (1986). Rearing of larvae of four coregonid

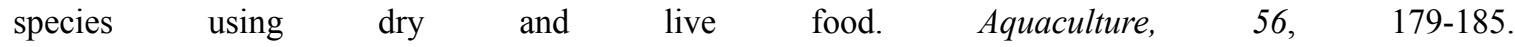
http://dx.doi.org/10.1016/0044-8486(86)90333-9

Mahmoudzadeh, H., Ahmadi, M. R., \& Shamsaei, M. (2009). Comparison of rotifer Brachionus plicatilis as a choice of live feed with dry feed in rearing Coregonus lavaretus fry. Aquaculture Nutrition, 15, 129-134. http://dx.doi.org/10.1111/j.1365-2095.2008.00575.x

Rissanen, I. (1995). The favourable feeding rate of whitefish (Coregonus lavaretus L. S. L.) in first feeding at $11{ }^{\circ} \mathrm{C}$ temperature. Arch. Hydrobiol. Spec. Issues Advanc. Limnol., 46, 325-330. http://dx.doi.org/10.1016/0044-8486(82)90075-8 
Rojas Beltran, R., Champigneulle, A., Gillet, C., \& Le Rouilly, N. (1992). Influence of egg source, initial characteristics, and rearing conditions on the growth, survival and development of Coregonus lavaretus $L$. larvae initially fed on a dry diet. Polskie Archiwum Hydrobiologi, 39, 683-691.

Rösch, R. (1988). Mass rearing of Coregonus lavaretus on a dry diet. Finnish Fisheries Research, 9, 345-351.

Rösch, R. (1992). Food intake and growth of larvae of Coregonus lavaretus: Effect of diet and light. Polskie Archiwum Hydrobiologi, 39, 671-676.

Rösch, R., \& Dabrowski, K. (1986). Tests of artificial food for larvae of Coregonus lavaretus from Lake Constance. Arch. Hydrobiol. Beih. Ergebn. Limnol., 22, 273-282.

Siikavuopio, S., Knudsen, R., Amundsen, P., \& Stainar Saether, B. (2012). Growth performance of European whitefish (Coregonus lavaretus $(L)$.$) under a constant light and temperature regime. Aquaculture Research,$ 43, 1592-1598. http://dx.doi.org/10.1111/j.1365-2109.2011.02963.x

Susta, J. (1888). Die Ernährung des Karpfens und seiner Teichgenossen. In neue Grundlagen der Teichwirtschaft (p. 252). Herrcke \& Lebeling.

Winkler, K., Pamminger-Lahnsteiner, B., Wanzenböck, J., \& Weiss, S. (2011). Hybridization and restricted gene flow between native and introduced stocks of Alpine whitefish (Coregonus $s p$.) across multiple environments. Molecular Ecology, 20, 456-472. http://dx.doi.org/10.1111/j.1365-294x.2010.04961.x

Yúfera, M., Kolkovski, S., Fernández-Diaz, D., et al. (2002). Free amino acid leaching from a protein-walled microencapsulated diet for fish larvae. Aquaculture, 214, 273-287. http://dx.doi.org/10.1016/s0044-8486(01)00902-4

\section{Copyrights}

Copyright for this article is retained by the author(s), with first publication rights granted to the journal.

This is an open-access article distributed under the terms and conditions of the Creative Commons Attribution license (http://creativecommons.org/licenses/by/3.0/). 